\title{
An extension of the improving and embedding project management practice framework - case study analysis
}

\author{
Abstract \\ Purpose - The present research develops and tests an extension of a previously \\ conceived framework for improving and embedding project management practice \\ in organisations. The framework identifies the most useful project management \\ improvement initiatives and the key factors for embedding project management \\ practice. However, professionals need guidance on how to operationalise such \\ framework in their organisations, therefore a method for applying the framework \\ is developed.
}

Design/methodology/approach - The method being proposed for applying the framework is demonstrated and tested with a large University-Industry consortium case study. During the case study analysis three research methods were applied: participant observation, document analysis, and focus groups.

Findings - In what concerns both the project management improvement initiatives and key embedding factors in the framework, the proposed method comprises their acknowledgment, scoring, relevance analysis, selection, and planning. The detailed report on how the framework was applied in the particular case study also sheds light on how University-Industry consortiums can make use of project management to become more successful.

Research limitations/implications - The research was performed using only one case study which limits the generalisability of its findings.

Practical implications - Detailed guidance is provided for applying the framework's both constructs, 'improving' and 'embedding', through a set of clear steps.

Originality/value - The paper shows the explanatory power of the framework for improving and embedding project management practice in a case study, demonstrating that the method for its application is practical and suitable.

Keywords: improving; embedding; project management practice; case study application 


\section{Introduction}

With the growing competition in the market, its quick changes and constant technological development, it is fundamental to have efficient project management (PM) practices to help organisations anticipate, respond and change constantly (Badewi, 2016; Silvius, 2016). Several studies have been conducted to demonstrate the value of PM (Carvalho et al., 2015; Joslin and Müller, 2015; Lappe and Spang, 2014; Mir and Pinnington, 2014; Thomas and Mullaly, 2008; Zhai et al., 2009). For many companies, improving PM practices is crucial to survival in this fast-changing environment (Ebert and Man, 2008). While the literature on PM provides some advice, organisations need guidance on which project management improvement initiatives (PMIIs) they should concentrate their efforts towards enhancing their overall performance (Shi, 2011; Thomas and Mullaly, 2008). A related issue is how to facilitate the embedment of PMIIs in organisations, of which there is limited understanding (Cranefield and Yoong, 2009). Therefore, a framework for improving and embedding PM practice was conceived and validated (Fernandes et al., 2014).

The framework considers that the two concepts 'improving PM practice' and 'embedding PM practice' are different, as illustrated in Fig. 1. 'Improving PM practice' focus on the identification of key PMIIs. PMIIs include specific PM practices that practitioners use to "execute a process", such as Work Breakdown Structure or Earned Value Management, as well as, and particularly, the development of activities that would help to improve PM practices, such as: i) the standardisation of PM processes, tools and techniques; ii ) the designation of formal titles and roles for those in charge of projects, and their adequate training; or iii) the alignment of PM activities with the whole organisation's activities (for example, the strategic planning of the organisation should be tightly coupled with the project identification and prioritisation). 'Embedding 
PM practice' focus on the identification of key facilitating factors, during the embedding process (diffusion, dissemination, implementation and routinisation) that can foster PM practices embedment.

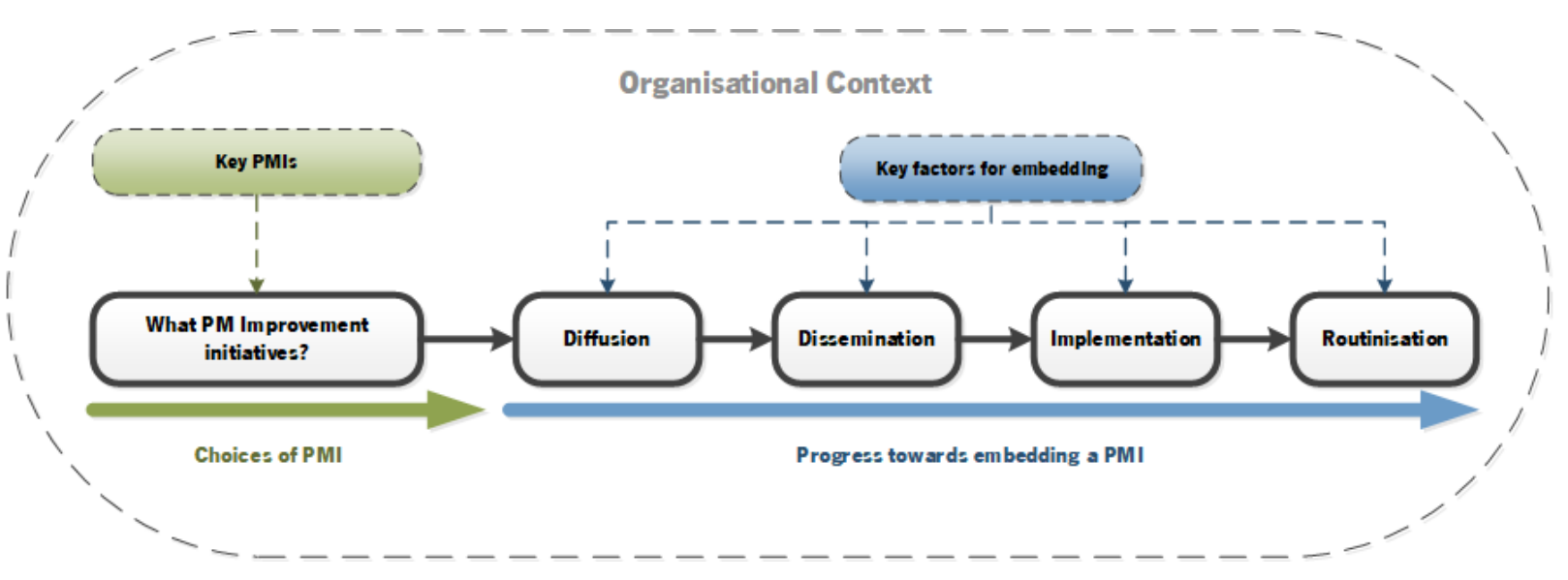

Figure 1. Conceptualisation of 'improving' and 'embedding' PM practice in organisations adapted from (Fernandes et al., 2015).

The framework was originally conceived in order to be applied to any kind of organisation interested in increasing its performance in the management of projects, being it constituted by a single company or institution or a consortium between different institutions, provided that at least one or more of the organisation members perceives the value of improving PM practice to increase the overall project performance. However, professionals need guidance on how to apply such framework in their organisations, since the published framework presents two high level constructs, 'improving' and 'embedding' (see Fig. 2 in Section 2), thus requiring its in-depth study to effectively ensure a proper implementation of those constructs into the organisational context. PM professionals, as any other professionals, need to adopt easy and understandable tools (Venkatesh and Bala, 2008). When PM professionals are challenged to use such framework, they question, for example, to which key PMIIs presented in the framework should the organisation give priority, or how can they explore the key embedding factors. Therefore, the main objective of this paper is to develop a method for the application of the framework by demonstrating and testing it through its use in a real case study. Particularly, the paper seeks to answer the following research question: How to implement and assess PM practice and its embeddedness in organisations? 
The case study selected is a University-Industry consortium, between University of Minho (UMinho) and Bosch Car Multimedia in Portugal (Bosch). The case study was selected by convenience relying on two sorts of reasons. On one hand, the University-Industry consortium - IC-HMI - was at the time the researchers' work context, where they have privileged access; on the other hand, both UMinho and Bosch, had identified among the main challenges on managing such R\&D collaborations, the difficulty in embedding PM practices in their systems.

Nevertheless, given the Grand Challenges of the 21st Century, University-Industry partnerships are expected to play an important role in it through the development of new products, technologies and processes for industry (Rohrbeck and Arnold, 2006). The collaborative research programmes or projects between industry and university are increasing (Perkmann et al., 2011) and are being encouraged by governments, namely through the funding of R\&D collaborative projects, as a means of enhancing national competitiveness and wealth creation (Barnes et al., 2002).

Literature research concerning University-Industry collaboration has concentrated primarily on the existence and effects of the so-called 'cultural gap' (Barnes et al., 2006). Barnes, Pashby and Gibbons (2006) suggest that the majority of the problems associated with the 'cultural gap' can be attenuated by good PM. Therefore, the use of this case study also brings light to how PM can help to reach successful University-Industry consortiums. However, it is not our intention to explicitly report in this paper research efforts in what concerns the adoption of PM practices in University-Industry settings.

The main benefit of the use of this case study to support the research described here is due to the fact that University-Industry consortiums bring additional complexity for embedding PM practice, since we are dealing with two different organisational structures with completely different cultures, which have joined together to pursue the objectives of the collaborative $R \& D$ project or program of projects (Brocke and Lippe, 2015). The fast embedment of PM practices in consortium organisations becomes even more crucial than in "traditional" organisations, 
because they are temporary organisations. They were created to achieve clearly defined objectives in a short time span when compared to the life cycle of traditional organisations.

In summary, organisations need more guidance on which PMIIs they should concentrate their efforts on and how to facilitate the embedment of PMIIs in their systems; as well as on how to apply a framework (Fernandes et al., 2014) that was developed with that specific purpose. The research reported here is an attempt to provide such guidance. As claimed by Svejvig and Andersen (2015) more practice-oriented studies are need, and this study aims to convince practitioners of how practical and valuable is the application of a specially framework for improving and embedding PM practice.

The paper follows a common structure. The second section gives the theoretical background of the study, by making a synopsis of the framework for improving and embedding PM practice, and the relation to existing theories. The third section describes the research methodology applied in this study, namely the University-Industry consortium case study efforts on improving PM practice. The fourth section presents the proposed method for the application of the framework for improving and embedding PM practice in organisations. The fifth section specifies the results of the application of the framework for the both constructs: 'improving' and 'embedding' PM practice. Finally, the main findings that emerged from this study, as well as the conclusions and suggestions for future work are discussed.

\section{Theoretical background}

\subsection{Synopsis of the framework for improving and embedding PM practice}

The framework for improving and embedding PM practice is conceptualised into two constructs: 'improving' and 'embedding' PM practice, although the two concepts are linked since an organisation engaged in embedding a PMII is consequently improving PM (see Fig. 2). However, in the framework conceptualisation 'improving' is seen as the identification and selection of potentially useful PMIIs which must then be embedded into the organisation to be effective. Therefore, with respect to the 
'improving' construct, it identifies the most useful PMIIs, particularly the key activities that would help to improve PM practice, such as the standardisation of PM processes, tools and techniques. In respect to the 'embedding' construct, the framework identifies factors contributing to the successful embedment of PMIIs. The assumption is that if an organisation is aware of these factors and addresses them during the stages of the embedding process of a PMII, i.e., sets actions to enhance their effect in the embedding process of a PMII, then embedment is more likely to be achieved.

In the development of the framework an "innovation lens" perspective was adopted, using concepts of diffusion, dissemination, implementation and routinisation, from other disciplines (Greenhalgh $e$ al., 2004; Venkatesh and Bala, 2008) to develop an understanding of the process of embedding PMIIs in organisations. The process of embedding PMIIs into organisations implies the diffusion, dissemination, implementation and routinisation of the PMII. Diffusion is the passive spread of PMIIs, whereas dissemination involves active and planned efforts to convince target groups to adopt a PMII. The implementation of the PMII includes active and planned efforts to incorporate a PMII within an organisation. The routinisation is the institutionalisation of a PMII, which is routinely used within an organisation, meaning that the PMII is embedded in the organisation. Therefore, embedding PMIIs is presented as a process rather than an event, whereas the embedment of PMIIs into the organisation is the result, i.e., one can say that a PMII is considered to be embedded in the organisation when: 1) a PMII is strongly contextualised (customised or personalised); 2) integrated with other contextualised management practices in the organisation; and 3) there is a sense of 'ownership' facilitated by the staff involvement at all levels.

Adopters have particular influence in the innovation process (Rogers, 2003), for example, recent studies have shown that organisational PM initiatives become 
embedded mainly through social contacts and peer-to-peer connections rather than through the establishment of formal processes (Dutton et al., 2014). However, some features of organisations (both structural and "cultural") have been shown to influence the likelihood that an innovation will be successfully implemented (Nystrom et al., 2002; Sharma and Rai, 2003), and factors beyond the organisation/external factors also play a role (Abrahamson and Fairchild, 1999; Johnston and Linton, 2000). The conducted process of diffusion, dissemination, implementation and routinisation also has an important influence on the embedment of innovations (Greenhalgh et al., 2004). In the framework (Fig. 2), the diffusion and dissemination of PMIIs is seen as the process of 'communication and influence' seeking the adoption of the PMII by the organisation. 'Implementation' comprises the set of efforts made to introduce the use of a PMII in the organisation. As argued by Meyers, Sivakumar and Nakata (1999, p. 295) implementation is "the early usage activities that often follow the adoption decision". The PMII implementation and routinisation success is also dependent on the organisational context (Cooke-Davies et al., 2009).

Therefore, while adopter features are an important group of factors to be considered, organisations should not neglect a broader perspective which considers inner context-related factors, outer context-related factors, communication and influence-related factors, implementation-related factors, and routinisation-related factors (Fig. 2). This expanded list of facilitating factors can act as levers that organisations can use in devising strategies to promote the embedment of PMIIs into their systems.

In summary, the framework for improving and embedding PM practice was developed in four main phases: 
(1) An 'initial framework' of key PMIIs and key embedding factors was derived from the literature (e.g., Greenhalgh et al., 2004; Shi, 2011; Venkatesh and Bala, 2008) and the researchers' professional experience.

(2) A 'revised framework' was constructed following an exploratory study, consisting of thirty semi-structured interviews with PM practitioners. More detailed information on the development of the 'revised framework' from the interviews data analysis (new, confirmed, merged and discredited factors) can be found in the paper (Fernandes et al., 2015).

(3) 793 responses from a worldwide web-based questionnaire were analysed to test the 'revised framework' and produce a 'refined framework'.

(4) The final 'proposed framework', called Framework for improving and embedding PM practice in organisations, see Fig. 2, was derived from the consolidation of interviews data and questionnaire survey data analysis. More detailed information on the questionnaire survey data analysis and development of the framework can be found in the paper (Fernandes et al., 2014).

The framework comprises 15 key PMIIs reduced into three 'improving' themes: 'processes, tools, and techniques', 'people and organisational learning' and 'general management system'; and 26 embedding factors reduced into six main 'embedding' themes: 'adopter', 'inner context', 'outer context' 'communication and influence (diffusion/ dissemination)', 'implementation', and 'routinisation'. 


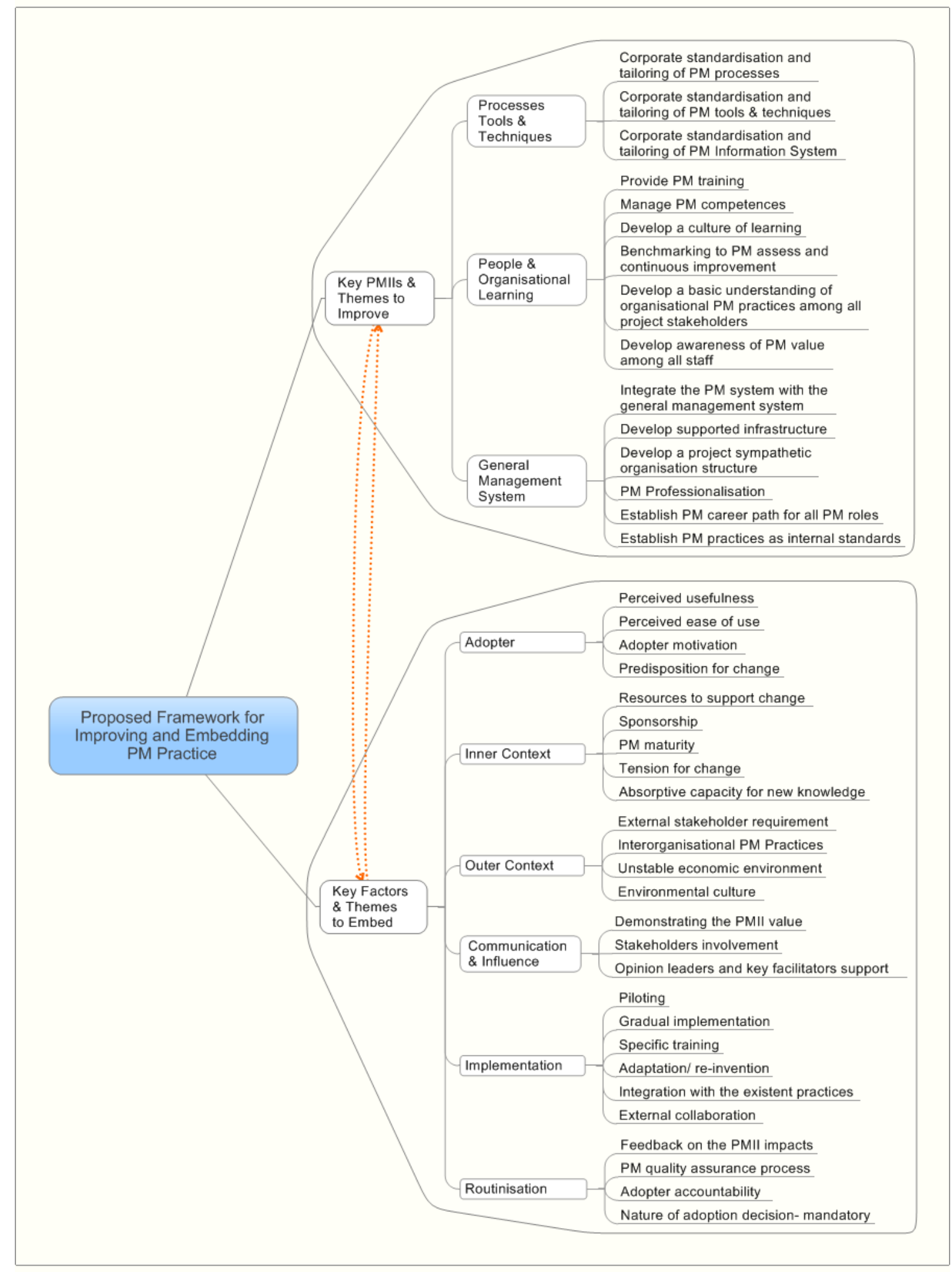

Figure 2. Framework for improving and embedding PM practice in organisations

from (Fernandes et al., 2014). 


\subsection{Relation to existing theories}

The research described in this paper takes into account the contingency theory (Van de Ven and Drazin, 1985), which is being applied in the PM area in the last three decades (Sauser et al., 2009). The contingency approach in PM investigates the extent of fit or misfit between project characteristics and PM (Hanisch and Wald, 2012; Sauser et al., 2009). Engwall (2003) emphasises the importance of a contingency approach and defends that projects are open systems dependent on history and organisational context.

Therefore, although the developed method proposed in this article aims to be generic independent on the organisational context, i.e. applicable in any organisation, the method takes into account the organisational context, and organisations should identify the relevance of each PMIIs for their own development. For example, information and technology companies might give more relevance (i.e. weight) to PMIIs, such as PM standardisation and tailoring of PM processes tools and techniques than Engineering and Construction companies, or small organisations might give more relevance to PMIIs under the theme 'People and Organisational Learning' than medium or large firms (Fernandes et al., 2019).

The developed method proposed here has as theoretical foundation the weighted scoring approach. The weighted scoring approach is a simple, direct, and effective to combine data terms (Bitman and Sharif, 2008), allowing the combination of both qualitative and quantitative criteria (Moore and Baker, 1969).

Weighted scoring approach requires a well-defined number for each criteria. However, frequently, the criteria used in weighted scoring approaches to perform an evaluation are subjective and may not be well defined (Cochran and Chen, 2005), hence the use of classifications such as "high", "medium" or "low" are common. Classifications of this kind frequently replace the well-defined numbers in the evaluation of features in a scoring approach (Cochran and Chen, 2005). 


\section{Case study methodology}

One popular classical research approach in management is to carry out quantitative investigations (Ottosson, 2003). However, quantitative research is affected by several limitations when applied to management research, such as the uniqueness of management processes in industry, as well as requiring mostly retrospective data analysis (Creswell, 2014). The call for a more intensive use of interpretive/qualitative methods in management research is not new, but has been increasing in the last decade.

The case study is one of the most used research strategies by researchers following a qualitative approach (Yin, 2014); and is increasingly being used for building theories (Eisenhardt and Graebner, 2007). The case study was considered the most appropriate research strategy, because by using it, on one hand, the researchers can focus in particular phenomena and discover crucial knowledge (Saunders et al., 2016) to give guidance on how to implement and assess PM practice and its embeddedness in organisations; on the other hand, it was possible to demonstrate in practice the usefulness and ease of use of the framework for embedding useful PMIIs in organisations.

Although PM is dependent on the organisational context, such as the structure of business or the industry sector, size, and its environment, and project typology, such as internal or external projects (Besner and Hobbs, 2008, 2013; Cooke-Davies et al., 2009; Hoobs and Besner, 2016; Hobbs et al., 2008), and therefore different organisations would perceive different relevance on the PMIIs and factors for promoting the embedment of PM practices in their organisations; the proposed method for applying the framework presented in this paper is generic, independent on the context and so the use of a different case study would also result into a similar proposed enhanced method. 


\subsection{Case study background}

The University-Industry consortium that has been chosen for the case study to show the application of the framework is named IC-HMI - A R\&D collaborative funded program - which resulted from a strategic partnership established between University of Minho (UMinho) and Bosch Car Multimedia Portugal S.A. (Bosch) in July 2012, regarding the development and production of advanced car multimedia solutions.

UMinho is currently among the most prestigious institutions of higher education in Portugal, and is in the top 100 universities under 50 years old $\left(75^{\text {th }}\right.$ position $)$ worldwide. Founded in 1973, UMinho is engaged in the valorization of the knowledgeresearch chain, development and innovation. UMinho stands out by the volume of publications and by the number of requested patents, as well as by the high collaboration with industry, around $250 \mathrm{R} \& \mathrm{D}$ contracts with industry are signed annually.

Bosch is located in Braga, Portugal, and was founded in 1990. Over the years, Bosch has become one of the biggest suppliers for automotive industry and the leading plant of the Car Multimedia division unit of Bosch Group. Presently, Bosch produces a wide portfolio of products, such as navigation systems, instrumentation systems, car radios, steering angle sensors, and electronic controllers. In 2015, Bosch achieved a turnover of around 516 million Euros, 99\% for export, with around two thousand jobs.

The IC-HMI program is the result of two public funded applications, Innovcar and iFactory. IC-HMI program foresees an investment of $€ 54.7$ million, from July 2015 to June 2018, with the admission of 94 new staff dedicated to R\&D in Bosch and 173 new researchers in UMinho. The IC-HMI program has planned 417 deliverables, the submission of 22 patent applications until June 2018 and 72 technical and scientific publications until June 2021.

The main benefits expected under the IC-HMI program are: 
- Bosch: (i) business and products diversification as a driver for sustained growth;

(ii) consolidation of Bosch reputation among customers and within Bosch Group itself; (iii) increase the international accumulated sales volume (2019-2025) by around 1.1 billion euros, with new business areas and new portfolio of products generated within the IC-HMI context.

- UMinho: (i) recognition by the scientific community as the holder of the knowledge of technologies and methodologies developed in the different dimensions of R\&D program; (ii) strengthening the scientific and technological knowledge transfer into industry.

\subsection{Case study efforts on improving PM practice}

UMinho and Bosch have perceived the value of PM to support management of such collaborative University-Industry R\&D funded program; and therefore, have invested in a support infrastructure of the type Project Management Office - named Program and Project Management Office (PgPMO). According to Müller, Glückler and Aubry (2013), the proposed PgPMO has a serving role, since its main objective is to support the Program Coordination Board and Project Teams during the program and project management life-cycle. The PgPMO takes responsibility for some of the project managers' tasks in order to reduce the workload of individual project managers and to benefit from the accumulated expertise and economies of scale (Artto et al., 2011). According to the framework for improving and embedding PM practice (see Fig. 2), the PgPMO is an attempt to "develop a supported infrastructure".

The PgPMO main responsibility, in the IC-HMI program initiation phase, was to propose the governance model for the IC-HMI program to the Program Coordination Board. The Program Coordination Board is composed of four people: the Program 
Directors, one from UMinho and another from Bosch, and the Program Managers, one from UMinho and another from Bosch as well. In fact, each IC-HMI organisation role has always a representative from Bosch and another from UMinho. The governance model proposed is based on a developed methodology specially devoted to program and project management of collaborative University-Industry R\&D funded contracts, named PgPM methodology (Fernandes et al., 2015, Fernandes et al., 2016).

The governance model presents the IC-HMI organisational structure, clarifying the functions and responsibilities of each organisation member, as well as standardising the main processes to support the management of the entire program and of its constituent projects. Specific guidance is given for each IC-HMI role, namely the steering committee member, program director, program manager, project manager, program and project management officer and team member, covering their main activities and responsibilities during the program and project life cycle. According to the framework for improving and embedding PM practice (see Fig. 2), part of the governance model is an attempt to "corporate standardisation and tailoring of PM processes".

The PgPMO, still in the program initiation phase, has made available to all program stakeholders a documentation management system, named inside.bosch. Later, during the execution of the program (program benefits delivery phase), the CAFE system (similar to Facebook) was also made available but completely restricted to ICHMI members, in order to explore social PM practices. As argued by Nach (2016), nowadays, project managers have the opportunity to go beyond conventional tools (e.g., email, shared files and repositories) to communicate; a project manager should learn and take advantage of social media within the PM practice. According to the framework for improving and embedding PM practice (see Fig. 2), the inside.bosch and CAFE 
systems are attempts to "corporate standardization and tailoring of PM information system".

\subsection{Research methods}

In conducting the case study, three research methods were applied: participant observation, document analysis, and focus groups.

In this research study, the observation method was adopted within a participative approach, since the researchers were inserted in the University-Industry consortium IC-HMI, and took part in the activities observed (Saunders et al., 2016). Since the researchers were aware that participant observation is more prone to researcher/observer bias (Baker, 2006; Saunders et al., 2016), they observed IC-HMI stakeholders in naturally occurring situations, namely during regular management and technical meetings and took notes. Thus, through participative and systematic observation, analysis and interpretation of behaviour, it was possible to grasp the organisational context (Angrosino, 2005).

However, participant observations has some disadvantages (Saunders et al., 2016), also experienced by the researchers in this study, it was very time consuming, the closeness of the researchers to participants being observed facilitated the access, however participant observer role was a very demanding one, namely in distinguish the role of colleague versus researcher. However, the researchers being aware of the potential bias, always tried to be critical about their perceptions in order to prevent its existence.

The analysis of several IC-HMI documents was also conducted to better understand the case study context, namely the case study efforts on improving PM practice. Among the most relevant documents analysed we can point out the established governance model for the IC-HMI program, the detailed roles of the PgPMO, as well as 
several documents that supported the management of the program and its constituent projects (e.g., project charters, technical and financial progress reports).

The focus group method was selected for this research design, because of its several advantages when compared to (individual) interviews and surveys. For example, focus groups allow participants to express their ideas/opinions freely and have the opportunity to discuss them with others simultaneously (Neuman, 2006). The discussion and participation is easier, since a participant's answers can be complemented by another one's, enriching the information (Fernandes and Machado, 2015). When is conducted a set of focus groups gives researchers the necessary time to reflect on the information they are getting and revise questions, if needed, in the following focus group (Krueger and Casey, 2014). These advantages were considered to largely compensate for drawbacks such as the risk of someone inhibiting the others, or someone being too shy to contribute. However, the researcher/moderator was aware of this issue and drew up her attention to less participative members, by maintaining eye contact, calling them by name, asking if they agree or disagree and seeking to have them express their own opinions (Stewart et al., 2007).

Two focus groups were conducted at different moments (November $28^{\text {th }} 2016$ and December $7^{\text {th }}$ 2016) with the same experts, both lasting approximately two hours. The first focus group was led to apply and discuss the framework's 'improving' construct, and the second focus group to apply and discuss the framework's 'embedding' construct.

The focus group consisted in gathering a group of experts to collectively apply the framework for improving and embedding PM practice in their organisation and provide their opinion on how to improve the method initially proposed for the framework's application (Krueger and Casey, 2014; Stewart et al., 2007). The two 
focus groups were led by the researcher and had the participation of eight experts three PgPMO Officers from UMinho, two PgPMO Officers from Bosch, the program manager from UMinho, one project manager from Bosch and project team member from UMinho, as indicated in Table 1. Note that Program and Project Management Officers (PgPMO Officers) had as a mission to support the IC-HMI Program Coordination Board and the Project Teams. The selection of the participating experts took into consideration their diversity, concerning the criteria: role, contractual relation, and considerable experience in PM in practice. However, the high proportion of PgPMO Officers participation is based on their role as the main elements responsible for improving and embedding PM practice at IC-HMI organisation.

Table 1. Expert group participants' characterisation.

\begin{tabular}{|l|l|l|l|l|l|}
\cline { 2 - 6 } \multicolumn{1}{c|}{} & Role & $\begin{array}{l}\text { Contractual } \\
\text { Relation }\end{array}$ & $\begin{array}{l}\text { PM } \\
\text { Experience }\end{array}$ & Gender & Age \\
\hline Participant 1 & Programme Manager & UMinho & $>20$ & Male & $40-50$ \\
\hline Participant 2 & Project Manager & Bosch & $10-15$ & Male & $>50$ \\
\hline Participant 3 & PMO Officer & Bosch & $5-10$ & Male & $40-50$ \\
\hline Participant 4 & PMO Officer & UMinho & $3-5$ & Female & $25-30$ \\
\hline Participant 5 & PMO Officer & UMinho & $3-5$ & Male & $30-40$ \\
\hline Participant 6 & PMO Officer & Bosch & $3-5$ & Female & $25-30$ \\
\hline Participant 7 & Team member & UMinho & $3-5$ & Female & $30-40$ \\
\hline Participant 8 & PMO Officer & UMinho & $1-3$ & Male & $30-40$ \\
\hline
\end{tabular}

The group discussed, in a planned way, the application of the framework at ICHMI organisation and how to improve the proposed method for the framework application. The preparation and conduction of the focus groups sessions are, in many aspects, similar to those of interviews. For instance, they involve preparing questions in advance and providing feedback on what one hears (Langford and McDonagh, 2003). The focus group moderator (researcher) used auxiliary materials, namely the initial proposed method for the application of the framework described in the next section (see Table 2), to stimulate the opinion of the participants. 
The data was collected by two note-takers who observed the entire sessions. Immediately after the focus groups meetings, the notes taken were reviewed jointly by the moderator (researcher) and the note-takers, in order to register and describe the observations that were not possible to list during the sessions. Subsequently, the participants were asked to validate and possibly add to these notes, if they were willing to do so. In some cases, the researchers highlighted parts of the notes that they would particularly like participants to check or expand upon. In the event, only $25 \%$ of participants made any additions to the notes.

\section{Proposed method for the framework extension}

As referred in Introduction Section, a framework for improving and embedding PM practice was previously developed; however, professionals need guidance on how to usefully and easily apply such framework in their organisations. During this study, a method has been created to give guidance on how professionals could make use of the framework for improving and embedding PM practice.

The extension of the framework for the 'improving' construct might be used to assess the organisation's PM maturity level differently than using conventional PM maturity models. PM maturity models are used to understand organisations' current capability to undertake PM and help them to improve PM practice in a structured way (Sowden eds., 2008) and consequently to improve project performance (Brookes et al., 2014), al. There are several maturity models for organisations to use available in the literature. For example, the Organisational Project Management Maturity Model $\left(\mathrm{OPM} 3{ }^{\circledR}\right)$ - Third Edition (PMI, 2013), the Portfolio, Programme, and Project Management Maturity Model (P3M3) from the Office of Government Commerce (Sowden eds., 2008), or the Berkeley project management maturity model (Ibbs and Reginato, 2002; Kwak and Ibbs, 2000). However, no single model has achieved general 
acceptance. In fact, it is questionable the value that PM maturity models, in their current form, actually deliver to improve project performance (Mullaly, 2014).

As argued by Thomas and Mullaly (2008) none of the existent maturity models had the depth and breadth of variables important to include in the evaluation of all aspects of PM. In addition, from a practical perspective, each of the instruments underlying these models runs into a large number of questions or items, most of which have never been tested for either their reliability or validity in scientific terms (Thomas and Mullaly, 2008). Additionally, as argued by Shi (2011), maturity models have a large number of indicators, which makes it hard for an organisation to implement and thus improve their PM practices. Therefore, while the literature on PM provides some advice, through for example, the use of PM maturity models (PMI, 2013; Sowden eds., 2008), organisations need guidance on which key PMIIs they should concentrate their efforts on (Shi, 2011; Zhai et al., 2009).

In summary, to the 'improving' construct, the proposal is to use a weighted scoring approach in order to assess PM maturity level in terms of the 15 PMIIs identified in the framework. The process of identification of the PM maturity level is similar to other existent maturity models, such as the Berkeley PM process maturity model (Kwak and Ibbs, 2000), namely in terms of the maturity assessment level. The main difference is the variables assessed, which are the 15 key PMIIs. Additionally, it involves prioritising the initiatives regarding their stage and organisational context, allowing the organisations to get a PM maturity index, and finally planning a set of actions in order to embed the PMIIs in the organisation.

As to the 'embedding' construct, the proposal is to use a weighted scoring approach to identify an index of readiness for embedding or stage of preparation "to make the things 
work", and plan a set of actions, involving people in thinking about what actions can be taken to activate the various embedding factors.

Table 2 presents the method, i.e., the steps that are suggested to be followed with a group of stakeholders involved in embedding PM practices in an organisation. As discussed to above, embedding is a process rather than an event, with different concerns being dominant at different stages of the embedding process (diffusion/ dissemination, implementation and routinisation) (Larsen and Myers, 1999).

Table 2. Proposed method for applying the framework ('improving' and 'embedding' constructs).

\begin{tabular}{|c|c|c|}
\hline Steps & 'Improving' Construct & 'Embedding' Construct \\
\hline $1^{\text {st }}$ & $\begin{array}{l}\text { Acknowledge } \text { stakeholders involved in the }^{1} \text { improving process of all the key PMIIs in the } \\
\text { framework which would improve PM } \\
\text { practice. }\end{array}$ & $\begin{array}{l}\text { Acknowledge }{ }^{1} \text { stakeholders involved in the } \\
\text { embedding process of all the key embedding } \\
\text { factors in the framework that can potentially } \\
\text { influence the embedding process of a } \\
\text { particular PMII. }\end{array}$ \\
\hline $2^{\text {nd }}$ & $\begin{array}{l}\text { Score all key PMIIs, from level } 1 \text { to level } 5 \text {, } \\
\text { in order to get an overall position of the } \\
\text { actual maturity of the organisation in relation } \\
\text { to the } 15 \text { key initiatives: } \\
\text { - Level } 1 \text { (Ad-hoc stage) - The key PMII is } \\
\text { not available in the organisation. } \\
\text { - Level } 2 \text { (Defined stage) - The key PMII is } \\
\text { informally defined and used. } \\
\text { - Level } 3 \text { (Managed stage) - The key PMII } \\
\text { is formally managed. } \\
\text { - Level } 4 \text { (Integrated stage) - The key PMII } \\
\text { is integrated. Data are quantitatively } \\
\text { analysed, measured and stored. } \\
\text { - Level } 5 \text { (Embedded stage) - The key } \\
\text { initiative is strongly contextualised and } \\
\text { integrated with other contextualised } \\
\text { management practices in the organisation } \\
\text { and there is a sense of 'ownership' } \\
\text { facilitated by the staff involvement at all } \\
\text { levels. The key PMII is fully understood } \\
\text { and continuously improved. }\end{array}$ & $\begin{array}{l}\text { Using a 5-Likert scale (5 - Very high; } 4- \\
\text { High; } 3 \text { - Medium; } 2 \text { - Low; } 1 \text { - Very low), } \\
\text { score }{ }^{2} \text { the framework's embedding factors that } \\
\text { have influence on the particular embedding } \\
\text { process stage of the PMII, if in: } \\
\text { - Diffusion/Dissemination stage - score the } \\
\text { factors relating to the themes: 'adopter', } \\
\text { 'inner context', 'outer context' and } \\
\text { 'communication \& influence'. } \\
\text { - Implementation stage - score the factors } \\
\text { relating to the themes: 'adopter', 'inner } \\
\text { context', 'outer context', 'communication } \\
\text { \& influence', and 'implementation'. } \\
\text { - Routinisation stage - score the factors } \\
\text { relating to the themes: 'adopter', 'inner } \\
\text { context', 'outer context', 'communication } \\
\text { \& influence', 'implementation' and } \\
\text { 'routinisation'. }\end{array}$ \\
\hline $3^{\text {rd }}$ & $\begin{array}{l}\text { Assess the relevance of the PMIIs for the } \\
\text { organisation, giving each one a weight } \\
\text { between 0- } 100 \% \text {. For simplicity a fixed } \\
\text { scale } 25 \%-50 \%-75 \% \text { and } 100 \% \text { might be } \\
\text { used. Assessing the organisation's PM } \\
\text { maturity level in terms of the } 15 \text { PMIIs } \\
\text { identified in the framework. }\end{array}$ & $\begin{array}{l}\text { Depending on the embedding process stage of } \\
\text { a particular PMII, prioritise the relevance of } \\
\text { the embedding factors, giving each one a } \\
\text { weight between } 0-100 \% \text {. For simplicity a } \\
\text { fixed scale } 25 \%-50 \%-75 \% \text { and } 100 \% \text { might } \\
\text { be used. Identifying a score of readiness for } \\
\text { embedding a particular PMII. }\end{array}$ \\
\hline $4^{\text {th }}$ & $\begin{array}{l}\text { Select the PMIIs your organisation will } \\
\text { handle and prioritise }{ }^{3} \text {. }\end{array}$ & $\begin{array}{l}\text { Answer the question: Can these embedding } \\
\text { factors be operationalised? }\end{array}$ \\
\hline
\end{tabular}




\begin{tabular}{|c|l|l|}
\hline Steps & \multicolumn{1}{|c|}{ 'Improving' Construct } & \multicolumn{1}{c|}{ 'Embedding' Construct } \\
\hline $5^{\text {th }}$ & $\begin{array}{l}\text { Answer the question: What are the main } \\
\text { action(s) for operationalising the PMIIs } \\
\text { selected in the organisation? Define } \\
\text { action(s). }\end{array}$ & $\begin{array}{l}\text { Answer the question: How can we enhance } \\
\text { the effect of the factors in the embedding } \\
\text { process of this particular PMII? Identify } \\
\text { appropriate action(s). }\end{array}$ \\
\hline $\mathbf{6}^{\text {th }}$ & $\begin{array}{l}\text { Depending on the assessment period } \\
\text { established (3, } 6 \text { or } 12 \text { months), re-score each } \\
\text { PMII, i.e., go back to the } 2^{\text {nd }} \text { step. The } \\
\text { organisation should stop this process when } \\
\text { perceiving that its target PM maturity level } \\
\text { has been reached. }\end{array}$ & $\begin{array}{l}\text { Depending on the embedding process } \\
\text { progress }{ }^{4} \text { (diffusion/dissemination, } \\
\text { implementation or routinisation), re-score the } \\
\text { embedding factors that have influence on that } \\
\text { stage, i.e., go back to the } 2^{\text {nd }} \text { step. The } \\
\text { organisation should stop this process when the } \\
\text { organisation perceives that the particular PMII } \\
\text { is embedded at the organisation. }\end{array}$ \\
\hline
\end{tabular}

${ }^{1}$ It could be facilitated, for example, through a training course "on the use of the framework for improving and embedding PM practice.

${ }^{2}$ For example, for the embedding factor "perceived ease of use", what is the actual adopters' perceived ease of use of the particular PMII selected? Or the embedding factor 'resources to support change' what is the actual level of resources available to support change? (5 - Very high; 4 - High; 3 - Medium; 2 - Low; 1 - Very low).

${ }^{3}$ Note that a gradual implementation of initiatives is important in order to better manage the expectations and benefits of each initiative.

${ }^{4}$ For example, the "perceived usefulness" of an PMII, may be scored low at the beginning of the embedding process but after actions taken, could be scored high, indicating that no more actions that have direct impact on "perceived usefulness" are needed or would have impact on the embedment of the PMII.

The guidance given on how practitioners could make use of the framework has some limitations, namely the subjectivity of the weighted scoring approach, i.e., the attributed score for each PMII and embedding factor and the \% of relevance of each PMII and embedding factor. Therefore, it is suggested that this process be conducted by a group of stakeholders. The group of participants should comprise members involved in the projects environment, in different levels of the organisational hierarchy (directors, portfolio, program and project managers, project sponsors and team members). In order to support the method implementation, a set of templates has also been created.

\section{Results of the framework application}

The results of the framework application derive from two focus group meetings. The first focus group was led to apply and discuss the framework's 'improving' construct, and the second focus group for the application and discussion of the framework 'embedding' construct. 
Before the conduction of the focus groups meetings, all participants had received by email a document named 'Introducing a Study on the Application of a Framework for Improving Embedding Project Management Practice', which clarified namely, the purpose of the study, and the research steps that would be followed during the focus group. At the beginning of each focus group session, the moderator (researcher) started by giving an introduction on the focus group purpose and how the session would be conducted. Also, specific printed material, namely the framework with the PMIIs and embedding factors descriptions, and the method created to give guidance on how the practitioners would make use of the framework, was distributed to the participants.

\subsection{First focus group: 'improving' construct}

The first focus group conducted dealt with the application of the framework's 'improving' construct, following the method, i.e., the steps initially suggested for its application (Table 2). Firstly, the moderator (researcher) gave a brief explanation on the key PMIIs in the framework's 'improving' construct, clarifying that additional information for each PMII could be consulted in the material provided at the beginning of the focus group. Secondly, the moderator asked the group elements to individually assess the state of each key PMII in the organisation, using a 5 point Likert-scale (see Table $2,2^{\text {nd }}$ Step), in order to get an overall position of the actual maturity of the organisation in relation to the 15 key initiatives. Thirdly, each of the group elements assessed the relevance of the PMIIs for the organisation, giving to each one a weight between 0 and $100 \%$. For an easier assessment, the moderator (researcher) suggested the use of a fixed scale $(25 \%, 50 \%, 75 \%$ and $100 \%)$ (see Table 2, $3^{\text {rd }}$ Step). After they concluded their own assessment, they were asked to discuss their evaluations and converge towards a consolidated assessment, on the basis of the score and weight of each PMII. 
Although the participants had different roles and experiences, it was possible, after a deep discussion, to agree on the score and weight values to assign to each PMII. As a result of these assessments (Table 3), it was possible to achieve a subjective measure of $\mathbf{1 , 9 8}$ for the PM maturity index of the UMinho and Bosch consortium - ICHMI in a scale of 1 to 5 .

Fourthly, the focus group participants were asked to prioritise and select the PMIIs that they would recommend to the organisation - IC-HMI to handle, bearing in mind that PMIIs gradual implementation is necessary in order to better manage the expectations and benefits of each PMII. Three initiatives were selected, as indicated in Table 3) "provide PM training”; 2) "develop awareness of PM value among all staff”; and 3) "integrate the PM system with the general management system". The rationality used by the focus group participants on the selection of the PMIIs was twofold - those that scored lower (1) and have greater relevance (100\%) for the organisation.

Table 3. Results of the application of the framework's 'improving' construct.

\begin{tabular}{|c|c|c|c|c|}
\hline Theme & PMII & $\begin{array}{l}\text { Score } \\
(1 \ldots .5) \\
\end{array}$ & Weight & $\begin{array}{l}\text { Selected } \\
\text { PMIIs } \\
\end{array}$ \\
\hline \multirow{3}{*}{ 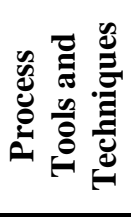 } & Corporate standardisation and tailoring of PM processes & 3 & $100 \%$ & \\
\hline & $\begin{array}{l}\text { Corporate standardisation and tailoring of PM tools \& } \\
\text { techniques }\end{array}$ & 3 & $100 \%$ & \\
\hline & $\begin{array}{l}\text { Corporate standardisation and tailoring of PM } \\
\text { information system }\end{array}$ & 2 & $100 \%$ & \\
\hline \multirow{6}{*}{ 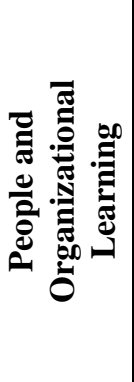 } & Provide PM training & 1 & $100 \%$ & $\mathrm{x}$ \\
\hline & Manage PM competences & 1 & $75 \%$ & \\
\hline & Develop a culture of learning & 2 & $100 \%$ & \\
\hline & $\begin{array}{l}\text { Benchmarking to PM assess and continuous } \\
\text { improvement }\end{array}$ & 2 & $75 \%$ & \\
\hline & $\begin{array}{l}\text { Develop a basic understanding of organisational PM } \\
\text { practices among all project stakeholders }\end{array}$ & 1 & $75 \%$ & \\
\hline & Develop awareness of PM value among all staff & 1 & $100 \%$ & $\mathrm{x}$ \\
\hline \multirow{6}{*}{ 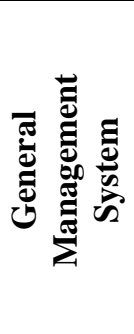 } & $\begin{array}{l}\text { Integrate the PM system with the general management } \\
\text { system }\end{array}$ & 1 & $100 \%$ & $\mathrm{x}$ \\
\hline & Develop supported infrastructure & 4 & $100 \%$ & \\
\hline & Develop a project sympathetic organisation structure & 3 & $75 \%$ & \\
\hline & PM professionalisation & 1 & $75 \%$ & \\
\hline & Establish PM career path for all PM roles & 1 & $75 \%$ & \\
\hline & Establish PM practices as internal standards & 3 & $100 \%$ & \\
\hline & PM MATURITY INDEX & \multicolumn{2}{|c|}{1,98} & \\
\hline
\end{tabular}


Lastly, they were asked to answer the question: what are the main action(s) for operationalising the PMIIs selected in the organisation?

(1) "Provide PM training". The main action to be taken is to provide different training courses, suited to the different needs of the different roles. Ideally, all ICI-HMI members would grasp the PM fundamentals, and thus, more advanced PM courses should be delivered to specific IC-HMI roles, such as the project manager, for example, on the specificities of managing University-Industry collaborations. The PgPMO could also provide coaching to project managers, giving real-time handson training on PM.

(2) "Develop awareness of PM value among all staff". The main action to be taken is to raise all program stakeholders awareness of why PM is important, and how PM contributes to the good operation and growth of the IC-HMI organisation namely through:

(2.1) Carrying out of workshop sessions to discuss how the PgPMO could effectively act as a supportive structure for project managers and team members.

(2.2) The creation and dissemination of a set of services that the PgPMO offers to the different IC-HMI roles. There is a general lack of knowledge by most of IC-HMI members on what activities the PgPMO can support.

(2.3) Increasing the visibility of the IC-HMI governance model. It is based on a developed methodology specially devoted to program and project management of collaborative University-Industry R\&D funded contracts. IC-HMI involves around 500 members, and most of them do not have any 
idea of the program and project management practices used to manage such complex initiative.

(3) "Integrate the PM system with the general management system". There are some possible actions to be taken, namely:

(3.1) Integrate into the IC-HMI governance model, based on the PgPM methodology, the processes that would guarantee the link between IC-HMI governance model and the general management systems of both consortium members, Bosch and UMinho: i) the benefits management, i.e., how the results obtained in the different projects that constitute the ICHMI program would transfer as effective benefits to both consortium members and ii) the strategic alignment of the collaborative research program with the involved partner members, Bosch and UMinho. For example, even if the IC-HMI program is of course considered as a strategic program for both organisations, Bosch and UMinho, the 30 projects that constitute the IC-HMI program were not selected from a larger portfolio of project ideas taking into account that criterion - the strategic alignment of each project with the strategy of Bosch and UMinho.

(3.2) Promote regular meetings with top management (administration, directions) of both consortium members in order to monitor the impact of the IC-HMI program in the respective organisations and to guarantee the sponsorship necessary for the different projects.

(3.3) Benchmark against the universe of consortiums that Bosch group has with other universities around the world, i.e., how do the Bosch consortiums 
integrate their PM practices with the general management system of consortium member's organisations?

For the continuous improvement of the organisational structure, i.e., to manage a PM maturity level increase, it was established a reassessment of the improving factors $\left(6^{\text {th }}\right.$ step) within a six month time frame. This cyclic process should be stopped when UMinho and Bosch consortium - IC-HMI perceives that it reached the target PM maturity.

\subsection{Second focus group: 'embedding' construct}

The second focus group conducted for the application of the framework's 'embedding' construct also followed the method initially suggested for its application (Table 2). Each PMII requires an individual analysis of its embedding process, thus the moderator (researcher) asked the participants to select only one of the three PMIIs selected to start the second focus group work.

The initiative selected was "integrate the PM system with the general management system" - through the implementation in the IC-HMI governance model, based on the PgPM methodology (Fernandes et al., 2015; Fernandes et al., 2016), of a benefits management process, i.e., how the results obtained in the different projects that constitute the IC-HMI program would transfer as effective benefits to both consortium members. Benefits are flows of value that arise from a project (Zwikael and Smyrk, 2012, Galan-Muros and Davey, 2017). As argued by Breese, Jenner, Serra, and Thorp (2015) focus on project benefits improves the success rate of projects and programs. Therefore, firstly, the moderator (researcher) started by giving a brief explanation to the focus group participants of the 26 key embedding factors, grouped in 6 themes (see Fig. 2). Secondly, the moderator asked them to assess, using a preestablished 5 -Likert scale, each embedding factor that has an influence during the 
implementation stage of the embedding process of the PMII selected. That is, score the embedding factors, relating to the themes: 'adopter', 'inner context', 'outer context', 'communication and influence' and 'implementation'. The factors related to the routinisation theme were not scored, in accordance with the guidance given in Table 2 stating that only the factors that have an influence on the particular embedding process stage should be scored. In this case, it was the implementation stage. For example, the embedding factor "perceived usefulness", to be scored from 1 to 5 , measures what is the actual adopters' perceived usefulness of a benefits management process implementation. Thirdly, the group participants were asked to assess the relevance of each key embedding factor for the embedding process of that specific PMII, giving each one a weight between 0 and $100 \%$. For an easier assessment, it was suggested by the moderator (researcher) the use of a fixed scale $(25 \%-50 \%-75 \%$ and $100 \%)$.

Although the participants had some divergences in the assessment of some embedding factors, at the end of the discussion they were able to reach an agreement (see Table 4). As a result of these two assessments, it was possible to achieve a subjective measure of $\mathbf{1 . 9 2}$ readiness for embedding index the initiative selected, in a scale of 1 to 5 .

Table 4. Results of the application of the framework's 'embedding' construct.

\begin{tabular}{|c|c|c|c|c|}
\hline Theme & Embedding Factor & $\begin{array}{c}\text { Score } \\
(1 \ldots .5) \\
\end{array}$ & Weight & Action \\
\hline \multirow{4}{*}{ 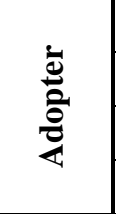 } & Perceived usefulness & 2 & $100 \%$ & $\mathrm{X}$ \\
\hline & Perceived ease of use & 1 & $50 \%$ & \\
\hline & Adopter motivation & 1 & $100 \%$ & $\mathrm{X}$ \\
\hline & Predisposition to change & 2 & $75 \%$ & $\mathrm{X}$ \\
\hline \multirow{5}{*}{ 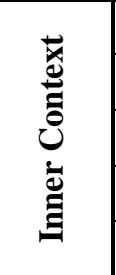 } & Resources to support change & 3 & $100 \%$ & \\
\hline & Sponsorship & 4 & $100 \%$ & \\
\hline & PM maturity & 2 & $75 \%$ & $\mathrm{X}$ \\
\hline & Tension for change & 2 & $75 \%$ & $\mathrm{X}$ \\
\hline & Absorptive capacity for new knowledge & 4 & $75 \%$ & \\
\hline \multirow{2}{*}{ 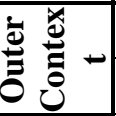 } & External stakeholder requirement & 2 & $50 \%$ & \\
\hline & Interorganisational PM practices & 1 & $25 \%$ & \\
\hline
\end{tabular}




\begin{tabular}{|c|c|c|c|c|}
\hline Theme & Embedding Factor & $\begin{array}{l}\text { Score } \\
(1 \ldots .5)\end{array}$ & Weight & Action \\
\hline & Unstable economic environment & 3 & $50 \%$ & \\
\hline & Environmental culture & 2 & $50 \%$ & \\
\hline \multirow{3}{*}{ 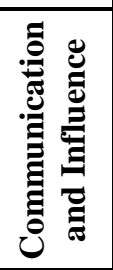 } & Demonstrating the PMII value & 1 & $75 \%$ & $\mathrm{X}$ \\
\hline & Stakeholders involvement & 2 & $75 \%$ & $\mathrm{X}$ \\
\hline & Opinion leaders and key facilitators support & 2 & $100 \%$ & $\mathrm{X}$ \\
\hline \multirow{6}{*}{ 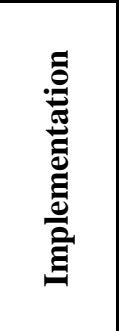 } & Piloting & 1 & $50 \%$ & \\
\hline & Gradual implementation & 1 & $50 \%$ & \\
\hline & Specific training & 1 & $75 \%$ & $\mathrm{X}$ \\
\hline & Adaptation/ re-invention & 1 & $100 \%$ & $\mathrm{X}$ \\
\hline & Integration with the existent practices & 1 & $75 \%$ & $\mathrm{X}$ \\
\hline & External collaboration & 1 & $25 \%$ & \\
\hline \multirow{5}{*}{ 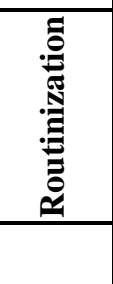 } & Feedback on the PMII impacts & - & - & \\
\hline & PM quality assurance process & - & - & \\
\hline & Adopter accountability & - & - & \\
\hline & Nature of adoption decision - mandatory & - & - & \\
\hline & READINESS FOR EMBEDDING INDEX & \multicolumn{2}{|c|}{1,92} & \\
\hline
\end{tabular}

Fourthly, they were asked to answer the following question: Can these embedding factors be operationalised? A positive answer to this question was obtained for 11 of the 26 embedding factors (indicated in the last column of Table 4).

Lastly, for the positively indicated embedding factors in Table 4, the question: How can we enhance the effect of these factors in the embedding process of this particular PMII? was answered by identifying appropriate actions.

Table 5 summarises the actions defined to enhance the effect of the embedding factors in the implementation stage of the embedding process of the particular PMII selected, "integrate the PM system with the general management system - through the implementation in the IC-HMI governance model, based on the PgPM methodology, of a benefits management process".

For the embedding process progress, in this particular PMII selected, from the PMII implementation to routinisation, it was established a reassessment of the 
embedding factors $\left(6^{\text {th }}\right.$ step $)$ in six months' time. This cyclic process should be stopped

when UMinho and Bosch consortium - IC-HMI perceives that the particular PMII is

embedded at the organisational structure.

Table 5. Major Actions suggested to enhance the effect of particular embedding factors.

\begin{tabular}{|c|c|c|}
\hline Theme & Embedding Factors & Actions \\
\hline \multirow{3}{*}{$\frac{\grave{0}}{\grave{2}}$} & Perceived usefulness & $\begin{array}{l}\text { - Conduct workshops to raise awareness of staff at all levels of the } \\
\text { organisation on the value of introducing a benefits management } \\
\text { process in the IC-HMI governance model, based on the PgPM } \\
\text { methodology. For example, the value of identifying and continually } \\
\text { pursuing the benefits resulting from the different projects. } \\
\text { - Share continuously the updated identified IC-HMI's benefits list } \\
\text { with all program stakeholders. }\end{array}$ \\
\hline & Adopter motivation & $\begin{array}{l}\text { - Reward the program stakeholders that bring greater benefits to the } \\
\text { consortium members, comply with the rules established in the } \\
\text { benefits management process and continually pursue benefits } \\
\text { delivery. }\end{array}$ \\
\hline & $\begin{array}{l}\text { Predisposition for } \\
\text { change }\end{array}$ & $\begin{array}{l}\text { - Provide coaching to the Program Coordination Board and project } \\
\text { managers, giving Real-time hands-on training on benefits } \\
\text { management. }\end{array}$ \\
\hline \multirow{2}{*}{ 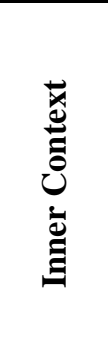 } & PM maturity & $\begin{array}{l}\text { - Increase the level of PM maturity through the implementation and } \\
\text { embedding of the three particular PMIIs selected during the } \\
\text { application of the 'improving' construct framework. }\end{array}$ \\
\hline & Tension for change & $\begin{array}{l}\text { Show that the economic environment is unstable and that the } \\
\text { introduction of innovative approaches to manage programs and } \\
\text { projects is needed, such as a benefits management process, in order } \\
\text { to increase their success, guaranteeing future programs and projects } \\
\text { collaborations between the University and Industry. }\end{array}$ \\
\hline \multirow{3}{*}{ 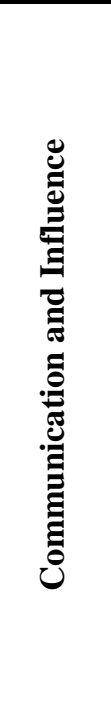 } & $\begin{array}{l}\text { Demonstrating the } \\
\text { PMII value }\end{array}$ & $\begin{array}{l}\text { - Communicate periodically the impacts of the systematic use of the } \\
\text { benefits management process to all Bosch and UMinho stakeholders, } \\
\text { namely through the communication of the benefits delivery, } \\
\text { increasing the probability of the Bosch-UMinho partnership } \\
\text { sustainability. }\end{array}$ \\
\hline & $\begin{array}{l}\text { Stakeholders } \\
\text { involvement }\end{array}$ & $\begin{array}{l}\text { - Gather feedback from all users (e.g., survey, focus group) of the } \\
\text { benefits management process established in the governance model, } \\
\text { based on the PgPM methodology, for its continuous improvement. } \\
\text { - Involve actively the governance model structures, program } \\
\text { coordination Board and program steering committee, in the } \\
\text { resolution of the projects' issues, not limiting them to a role of } \\
\text { program and project controllers, with a twice to three times per year } \\
\text { intervention. }\end{array}$ \\
\hline & $\begin{array}{l}\text { Opinion leaders and } \\
\text { key facilitators } \\
\text { support }\end{array}$ & $\begin{array}{l}\text { - Identify the opinion leaders on the program governance and persuade } \\
\text { them to encourage the adoption of the benefits management process } \\
\text { established in the governance model. }\end{array}$ \\
\hline 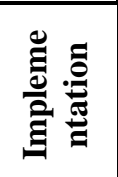 & Specific training & $\begin{array}{l}\text { - Train the program members, particularly the program manager and } \\
\text { project managers, for a good understanding of the benefits } \\
\text { management process within PgPM methodology, focusing on the } \\
\text { guides created for each role of the program governance. }\end{array}$ \\
\hline
\end{tabular}




\begin{tabular}{|l|l|l|}
\hline Theme & Embedding Factors & \multicolumn{1}{c|}{ Actions } \\
\hline & $\begin{array}{l}\text { Adaptation/ re- } \\
\text { invention }\end{array}$ & $\begin{array}{l}\text { - Involve the key stakeholders in the adaptation/ re-invention of the } \\
\text { benefits management process defined in the PgPM methodology to } \\
\text { the IC-HMI governance model context. }\end{array}$ \\
\cline { 2 - 3 } & $\begin{array}{l}\text { Integration with the } \\
\text { existent practices }\end{array}$ & $\begin{array}{l}\text { Integrate the benefits management process, in particular, with the } \\
\text { component of innovation management of the IC-HMI governance } \\
\text { structure. }\end{array}$ \\
\hline
\end{tabular}

\section{Discussion}

The results presented in this research study are exploratory. As is often the case with exploratory research, the results open up many avenues for improvement (Besner and Hobbs, 2012). Therefore, based on the problems occurred during the use of the proposed method for applying the framework for improving and embedding PM practice, this section further discusses possibilities to enhance this proposed extension of the framework. This is followed by a presentation of the strengths and limitations of the framework's extension and suggests future research initiatives.

\subsection{Enhancing the proposed method for the framework extension}

Table 6 briefly summarises the major issues and suggestions discussed during the conduction of the focus groups. These allowed to propose improvements to the initially proposed method for the application of the framework (Table 2 in Section 4), and they are presented in detail in the following paragraphs.

Table 6. Avenues for improving the proposed method for applying the framework.

1) Use of Delphi method

2) Rank in decreasing order of importance the PMIIs and embedding factors

3) Group should include participants belonging to all PM roles

4) Definitions of the scores 1 to 5 for each PMII in the 'improving' construct are necessary

5) Creation of a question to score 1 to 5 each embedding factor in the 'embedding' construct is necessary

\section{(1) Use of Delphi method}

Before trying to set a consensus on what score (1 to 5) to assign to each key PMII and embedding factor, and its selection, using a focus group strategy, it might be better to 
conduct an individual assessment with each participant, in order to reduce the influence of other participants in her/his own assessment. Therefore, the Delphi method would be recommended for the first steps of the framework application and complemented by a focus group for the $5^{\text {th }}$ step, which would aim to answer the following questions: What are the main action(s) for operationalising the PMIIs selected in the organisation? ('improving' construct) and How can we enhance the effect of the factors in the embedding process of this particular PMII? ('embedding construct').

This way the quantitative nature of the first four steps of the method proposed could be better answered using a strategy that requires quantitative consensus evaluation, such as Delphi. The $5^{\text {th }}$ step, clearly having a different nature, requiring analysis and discussion of different procedures to operationalise the PMIIs ('improving' construct) and the actions to enhance the effect of the embedding factors ('embedding' construct), could be fostered using a qualitative approach, where different opinions could be explored and their pros and cons discussed, in a reduced time session, such as a focus group strategy.

It is expected that the complementary strengths of both methods: Delphi and focus group, namely the capability to get higher confidence on the consensus obtained from the Delphi method (Rowe et al., 1991), and the focus group advantage of easing the discussion and participation, since the answers of a participant can be complemented by others, enriching the information (Fernandes and Machado, 2015), it would help to improve the effectiveness of applying the framework for improving and embedding PM practice in organisations.

\section{(2) Rank in decreasing order of importance the PMIIs and embedding factors}

The weight attributed to each PMII was higher than expected. For all 15 key PMIIs a weight between $75 \%$ and $100 \%$ was attributed. On the one hand, it shows the usefulness 
recognized by the focus groups' participants of the 15 key PMIIs identified in the framework, on the other hand, it makes it difficult to prioritise and select which PMIIs to handle afterwards. Therefore, instead of the suggested weighting of each PMII and embedding factor in a fixed scale of $25 \%-50 \%-75 \%$ and $100 \%$, as defined in the initial guidance of the framework (see Table $2,3^{\text {rd }}$ step), it seems better to rank in decreasing order of importance each PMII and each embedding factor, within each 'improving' and 'embedding' theme, and convert the rank in percentage only afterwards.

For example, the 'improving' theme 'people and organisational learning' has six key PMIIs, so each would be scored from 1 to 6, in which 6 corresponds to the highest importance of each PMII in the theme; similarly, the six PMIIs in the theme 'general management system' would be scored from 1 to 6 , and the three PMIIs in the 'process, tools and techniques' theme would be scored from 1 to 3 . In order to get a final subjective measure of the PM maturity, distribute the percentage of $0-100 \%$ by the three 'improving' themes. For example, participants might assign a percentage of $35 \%$ to the 'improving' theme 'processes, tools and techniques'; 40\% to the theme 'people and organisational learning'; and the remaining $25 \%$ to the theme "general management system".

No conclusion can be drawn about a "better suitability" of either system, based only on this case study. At this stage, we can propose both weighted scoring approaches and leave to the organisation the decision on which one to choose. Ideally, the running of both and subsequent comparison will add evidence in order to attain a more informed future prior selection.

(3) Group should include participants belonging to all PM roles 
The group of participants selected for the framework application should be composed by participants across all PM roles in the organisational structure. In this particular case study, the focus group was composed by eight experts - three PgPMO Officers from UMinho, two PgPMO Officers from Bosch, the program manager from UMinho, one project manager from Bosch and a project team member from UMinho. The IC-HMI program organisation is very complex, and it was not possible to engage at least a member of the program belonging to each different role, in spite of the importance attributed to such a representation.

Since the beginning of this research study, the researchers believed that different organisations (industry, size, strategy, geographic location, project types) place different relevance on different PMIIs and factors in promoting the embedment of PM practices in organisations. However, this case study showed that different relevancies are assigned by participants with different roles to the framework's key PMIIs and embedding factors. Sometimes, even the consensus among the few participants was difficult to achieve, i.e., it is dependent on the organisational context, but also seems to be dependent on the participant's role, and in this particular organisational structure IC-HMI, dependent on the specific affiliation, either to Industry (Bosch) or to University (UMinho).

Therefore, we stress the importance of a heterogeneous and larger group in this process, covering all PM roles, in order to address all stakeholders' needs, and in order to ensure a higher level of independent and unbiased assessments.

\section{(4) Definitions of the scores 1 to 5 for each PMII in the 'improving' construct are} necessary

Regarding the 'improving' construct, for the $2^{\text {nd }}$ step, the definitions of the scores 1 (adhoc stage) to 5 (embedded stage) seem to require more detail. In some PMIIs, the focus 
group participants found it difficult to assign a score based on the specified definitions (Table 2). Ideally, these definitions should be detailed for each PMII. The evaluation criteria should be more objective and well-defined as suggested by Cochran and Chen (2005).

(5) Creation of a question to score 1 to 5 each embedding factor in the 'embedding' construct is necessary

Finally, regarding the 'embedding' construct, also for the $2^{\text {nd }}$ step, the creation of a question to score 1 to 5 each embedding factor might help the participants in the assessment, especially if the Delphi method is to be used, wherein the moderator clarifications of what is intended to assess is more difficult to obtain. For example, for the embedding factor "perceived ease of use", what is the actual adopters' perceived ease of use of the particular PMII selected? Or for the embedding factor "resources to support change", what is the actual level of resources available to support change? (5 Very high; 4 - High; 3 - Medium; 2 - Low; 1 - Very low).

In spite of obtaining some suggestions for improving the method for applying the framework (discussed above) all the focus group participants agreed that the proposed method given in Table 2, i.e., the steps of the framework application ('improving' and 'embedding' constructs), are well conceptualised, were practical and suitable, and therefore should be followed. The suggested combination of the two data collection methods, the Delphi method for the first steps and the focus group for the $5^{\text {th }}$ step, would require extra time for the framework application. However, the clarification of the definitions of the scores 1 to 5 for each PMII in the 'improving' construct and the creation of a question to score 1 to 5 each embedding factor in the 'embedding' construct would reduce substantially the time necessary and subjectivity of the assessments. 


\subsection{Strengths and limitations of the framework extension}

One of the strengths is that this proposed method for extending the framework allowed the framework to be tested empirically. Testing the framework validates its own value in helping to organise empirical observations towards making sense of the field and understand its boundaries, major findings and challenges, as is the main goal of frameworks (Shapira, 2011).

Another strength of this extension of the framework is that it emphasises the importance of a contingency approach (Hanisch and Wald, 2012; Sauser et al., 2009) when improving PM practice in organisations. Highlighting the importance of organisations to assess the relevance of the PMIIs for the organisation, giving each one a weight between $0-100 \%$ (see Table 2).

However, even with this proposed method for extending the framework, we still note some limitations. A first limitation is that PM is highly contingent on the organisational context and project typology as it is well recognised in literature (Besner and Hobbs, 2013; Hoobs and Besner, 2016). Therefore, further applications of the framework through case studies will be very valuable, namely in observing how PMIIs are being implemented and understanding the weight that different practitioners in different organisations, by industrial sector, size, strategy, geographic location, project types, place on different PMIIs and factors for promoting the embedment of PM practice in organisations, taking a project-as-practice research perspective (Blomquist et al., 2010)."

A second limitation, is the still limited assistance given to organisations in facilitating the embedment of PMIIs within the framework's set of embedding factors, namely by exploring further strategies or sets of actions to complement the major actions suggested to enhance the effect of particular embedding factors selected in this case study (see Table 5). 


\section{Conclusions}

The research reported in this paper has both theoretical and practical contributions. The paper proposes and discusses a method for applying a framework for improving and embedding PM practice in organisations, making an important extension on the previously developed work (Fernandes et al., 2014). The method allows that the framework's 'improving' construct might be used as a PM maturity model, allowing organisations to identify their PM maturity index, and that the framework's 'embedding' construct be used to identify a readiness for embedding index of each project management improvement initiative (PMII) at the organisation. Moerover, the paper demonstrates/ exemplifies how professionals can make an easy use of the framework for embedding PMIIs in their organisations, given also an important contribution to PM practice. Therefore, with these theoretical (method for assessing a PM maturity index and a readiness for embedding index) and practical contributions (how to operationalise the application of the framework) the framework for improving and embedding PM practice in organisations, previously developed and published is extended, and the research loop around it is being closed.

The paper shows the explanatory power of a framework for improving and embedding PM practice in a University-Industry Consortium case study, aiming at increasing its program and projects' management performance. The framework highlights the need for the organisations to focus on a particular set of PMIIs that includes not just specific PM tools and techniques, but wider initiatives, such as the alignment of PM activities with the whole organisation's activities or the professionalization of the project manager's role. Additionally, the framework incorporates a number of factors that can facilitate the embedding of PMIIs. These embedding factors are a broad set comprising not just adopter-related factors, but also inner context, outer context, communication and influence, implementation, and 
routinisation-related factors. This set of facilitating factors indicates a set of levers that organisations can use to devise strategies to promote the embedding of PM practices into their systems.

Detailed guidance is given for the application of the framework for improving and embedding PM practice in a method format, i.e., detailed steps are provided for applying the framework's both constructs: 'improving' and 'embedding' (Table 2 in Section 4). During this research study, a set of templates has also been created to support the method implementation. Improvements on the initial proposed method were subsequently suggested throughout the case study development (summarised in Table $6)$.

The University-Industry Consortium case study has demonstrated that the application of the framework is easy and useful, able to improve and embed PM practice in the organisation. However, it remains to be decided by the top management if resources will be invested on the increase of the indexes values, or not. The organisation now becomes aware of its/their position in respect to their PM maturity index, and their readiness to embed each of the most relevant PMIIs. If they will proceed improving the indexes is their concern, and they have the tools to assess the progression.

Nevertheless, like any framework, it portrays a simplification of reality and should be used with caution. For example, in this particular case of consortium organisational structures, to pursue the PMII - 'establish PM career path for all PM roles' might not interest the specific consortium structure, since consortiums are temporary organisations, and therefore the relevance of the PMII for this particular organisational structures has most probably a weight of $0 \%$. Nevertheless, it is important to note that if the PM practice is effectively embedded in the consortium 
organisational structure, more easily the PM practice will cross the boundaries of the consortium to the consortium members' organisations.

Finally, the detailed report on how the framework was applied to the particular case study University-Industry Consortium also sheds light on how University-Industry consortiums can make use of PM to become more successful.

\section{Acknowledgement}

This work was supported by the FCT - Fundação para a Ciência e a Tecnologia; under Grant SFRH/BPD/111033/2015.

\section{References}

Abrahamson, E. and Fairchild, G. (1999), "Management Fashion: Lifecycles, Triggers, and Collective Learning Processes", Administrative Science Quarterly, Vol. 44 No. 4, pp. 708-740.

Angrosino, M. (2005), Recontextualizing observation: Ethnography, pedagogy, and the prospects for a progressive political agenda. In Denzin N. and Lincoln Y. (Eds.), The Sage Handbook of Qualitative Research 3rd ed., Sage, Thousand Oaks, pp. 729-745.

Artto, K., Kulvik, I., Poskela, J. and Turkulainen, V. (2011), "The integrative role of the project management office in the front end of innovation", International Journal of Project Management, Vol. 29 No. 4, pp. 408-421.

Badewi, A. (2016), "The impact of project management (PM) and benefits management (BM) practices on project success: Towards developing a project benefits governance framework", International Journal of Project Management, Vol. 34 No. 4, pp. 761-778.

Baker, L. (2006), “Observation: A complex research method”, Library Trends, Vol. 55 No. 1, pp. 171-189.

Barnes, T.A., Pashby, I.R. and Gibbons, A.M. (2006), "Managing collaborative R\&D projects development of a practical management tool", International Journal of Project Management, Vol. 24 No. 5, pp. 395-404.

Barnes, T.A., Pashby, I.R. and Gibbons, A.M. (2002), "Effective University - Industry Interaction: A Multi-case Evaluation of Collaborative R\&D Projects", European Management Journal, Vol. 20 No. 3, pp. 272-285.

Besner, C. and Hobbs, B. (2012), “An Empirical Identification of Project Management Toolsets and Comparasion Project Outcome: An empirical study", Project Management Journal, Vol. 43 No. 5, pp. 24-43. 
Besner, C. and Hobbs, B. (2008), "Project Management Practice, Generic or Contextual: A Reality Check”, Project Management Journal, Vol. 39 No. 1, pp. 16-34.

Besner, C. and Hobbs, B. (2013), "Contextualized Project Management Practice: A Cluster Analysis of Practices and Best Practices”, Project Management Journal, Vol. 44 No. 1, pp. 17-34.

Bitman, W.R. and Sharif, N. (2008), "A Conceptual Framework for Ranking R\&D Projects", IEEE Transactions on Engineering Management, Vol. 55 No. 2, pp. 267-278.

Blomquist, T., Hällgren, M., Nilsson, A., and Söderholm, A. (2010), "Project-aspractice: in search of project management research that matters", Project Management Journal, Vol. 41 No. 1, pp. 5-16.

Breese, R., Jenner, S., Serra, C. and Thorp, J. (2015), "Benefits management: Lost or found in translation", International Journal of Project Management, Vol. 33 No. 7, pp. $1438-1451$.

Brocke, J. and Lippe, S. (2015), "Managing collaborative research projects: A synthesis of project management literature and directives for future research", International Journal of Project Management, Vol. 33 No. 5, pp. 1022-1039.

Brookes, N., Butler, M, . Dey, P., Clark, R. (2014), "The use of maturity models in improving project management performance: An empirical investigation", International Journal of Managing Projects in Business, Vol. 7 No. 2, 231-246.

Carvalho, M.M., Patah, L.A. and Bido, D.S. (2015), "Project management and its effects on project success: Cross-country and cross-industry comparisons", International Journal of Project Management, Vol. 33 No. 7, pp. 1509-1522.

Cochran, J.K. and Chen, H.N. (2005), "Fuzzy multi-criteria selection of object-oriented simulation software for production system analysis", Computers \& Operations Research, Vol. 32 No. 1, pp. 153-168.

Cooke-Davies, T.J., Crawford, L.H. and Lechler, T.G. (2009), "Project management systems: Moving project management from an operational to a strategic discipline", Project Management Journal, Vol. 40 No. 1, pp. 110-123.

Cranefield, J. and Yoong, P. (2009), "Embedding personal professional knowledge in a complex online community environment", Online Information Review, Vol. 33 No. 2, pp. 257-275.

Creswell, J.W. (2014), Research Design: Qualitative, Quantitative, and Mixed Methods Approaches (4th ed.), Sage Publications Inc., Thousand Oaks.

Dutton, C., Turner, N. and Lee-Kelley, L. (2014), "Learning in a programme context: An exploratory investigation of drivers and constraints", International Journal of Project Management, Vol. 32 No. 5, pp. 747-758.

Ebert, C. and Man, J. (2008), "Effectively utilizing project, product and process knowledge", Information and Software Technology, Vol. 50 No. 6, pp. 579-594. 
Eisenhardt, K.M. and Graebner, M.E. (2007), "Theory Building From Cases: Opportunities And Challenges", Academy of Management Journal, Vol. 50 No. 1, pp $25-32$.

Engwall, M. (2003), "No project is an island: linking projects to history and context", Research Policy, Vol. 32 No. 5, pp. 789-808.

Fernandes, J.M. and Machado, R.J. (2015), Requirements in Engineering Projects, Lecture Notes in Management and Industrial Engineering, Springer.

Fernandes, G. and Araújo, M. (2019), "Improving and Embedding Project Management Practice: Generic or Context Dependent?", International Journal of Information Systems and Project Management, pp.1-20 (in press).

Fernandes, G., et al. (2016). "Perceptions of Different Stakeholders on Managing Collaborative University-Industry R\&D Funded Contracts", Procedia Computer Science, Vol. 100, pp. 878-887.

Fernandes, G., Pinto, E.B., Machado, R.J., Araújo, M. and Pontes, A. (2015), “A Program and Project Management Approach for Collaborative University-industry R\&D Funded Contracts", Procedia Computer Science, Vol. 64, pp. 1065-1074.

Fernandes, G., Ward S. and Araújo, M. (2015), "Improving and embedding project management practice in organisations - A qualitative study", International Journal of Project Management, Vol. 33 No. 5, pp. 1052-1067.

Fernandes, G., Ward S. and Araújo, M. (2014), "Developing a Framework for Embedding Useful Project Management Improvement Initiatives in Organizations", Project Management Journal, Vol. 45 No. 4, pp. 81-108.

Galan-Muros, V. and Davey, T. (2017), "The UBC ecosystem: putting together a comprehensive framework for university-business cooperation", The Journal of Technology Transfer (in press).

Greenhalgh, T., Robert, G., Macfarlane, F., Bate, P. and Kyriakidou, O. (2004), "Diffusion of Innovations in Service Organizations: Systematic Review and Recommendations”, Milbank Quarterly, Vol. 82 No. 4, pp. 581-629.

Hanisch, B. and Wald A. (2012), "A bibliometric view on the use of contingency theory in project management research", Project Management Journal, Vol. 43 No. 3, pp. 423.

Hobbs, B. and C. Besner (2016), "Projects with internal vs. external customers: An empirical investigation of variation in practice", International Journal of Project Management, Vol. 34 No. 4, pp. 675-687.

Hobbs, B., Aubry, M. and Thuillier, D. (2008), "The project management office as an organisational innovation", International Journal of Project Management, Vol. 26 No. $5,547-555$.

Ibbs, W. and Reginato, J. (2002), "Measuring the Strategic Value of Project management", Impresario of the Construction Industry Symposium 2002, Hong Kong. 
PMI (2013), Organizational Project Management Maturity Model $\left(O P M 3^{\circledR}\right)\left(3^{\text {rd }}\right.$ ed.), PA: Project Management Institute, Inc, Newtown Square.

Johnston, D.A. and Linton, J.D. (2000), "Social Networks and the Implementation of Environmental Technology", IEEE Transactions on Engineering Management, Vol. 47 No. 4, pp. 465-477.

Joslin, R. and Müller, R. (2015), "Relationships between a project management methodology and project success in different project governance contexts", International Journal of Project Management, Vol. 33 No. 6, pp.1377-1392.

Krueger, R.A. and Casey, M.A. (2014), Focus groups: A practical guide for applied research $\left(5^{\text {th }}\right.$ ed.), Sage Publications, USA.

Kwak, Y.H. and Ibbs, C.W. (2000), "The Berkeley project management process maturity model: measuring the value of project management", in Engineering Management Society Conference 2000 proceedings of the 2000 IEEE Albuquerque, NM, USA.

Langford, J. and McDonagh, D. (2003), Focus Groups: Supporting Effective Product Development, Taylor \& Francis, New York.

Larsen, M.A. and Myers, M.D. (1999), "When success turns into failure: a packagedriven business process re-engineering project in the financial services industry", The Journal of Strategic Information Systems, Vol. 8 No. 4, pp. 395-417.

Meyers, P.W., Sivakumar, K. and Nakata, C. (1999), "Implementation of industrial process innovations: factors, effects, and marketing implications", Journal of Product Innovation Management, Vol. 16 No. 3, pp. 295-311.

Mir, F.A. and Pinnington, A.H. (2014), "Exploring the value of project management: Linking project management performance and project success", International Journal of Project Management, Vol. 32 No. 2, pp. 202-217.Moore, J.R. and Baker, N.R. (1969), "An analytical approach to scoring model design - Application to research and development project selection", IEEE Transactions on Engineering Management, Vol. 16 No. 3, pp. 90-98.

Mullaly, M. (2014), "If maturity is the answer, then exactly what was the question?", International Journal of Managing Projects in Business, Vol. 7 No.2, pp.169-185.

Müller, R., Glückler, J. and Aubry, M. (2013), “A Relational Typology of Project Management Offices”, Project Management Journal, Vol. 44 No. 1, pp. 59-76.

Nach, H. (2016), "Project Management 2.0: Towards the Renewal of the Discipline". In G. Silvius (Ed.), Strategic Integration of Social Media into Project Management Practice, IGI Global, pp.1-15.

Neuman, W.L. (2006), Social Research Methods - Qualitative and Quantitative Approaches. Pearson, Education, Inc, Boston. 
Nystrom, P.C., Ramamurthy, K. and Wilson, A.L. (2002), "Organizational context, climate and innovativeness: adoption of imaging technology", Journal of Engineering and Technology Management, Vol. 19 No. 3-4, pp. 221-247.

Ottosson, S. (2003), "Participation action research: A key to improved knowledge of management", Technovation, Vol. 23 No. 2, pp. 87-94.

Lappe, M. and Spang K. (2014), "Investments in project management are profitable: A case study-based analysis of the relationship between the costs and benefits of project", International Journal of Project Management, Vol. 32 No. 4, pp. 603-612.

Perkmann, M., Neely, A. and Walsh, K. (2011), "How should firms evaluate success in university-industry alliances? A performance measurement system", $R \& D$ Management, Vol. 41 No. 2, pp. 202-216.

Rogers, E.M. (2003), Diffusion of Innovations (5th ed.), Free Press, New York.

Rohrbeck, R. and Arnold, H. (2006), "Making university-industry collaboration work a case study on the Deutsche telekom laboratories contrasted with findings in literature?", in ISPIM Annual Conference, 2006 proceedings of the ISPIM Annual Conference, 2006 - Network Innovation.

Rowe, G., Wright, G. and Bolger, F. (1991), "Delphi: A reevaluation of research and theory”, Technological Forecasting and Social Change, Vol. 39 No. 3, pp. 235-251.

Saunders, M., Lewis, P. and Thornhill, A. (2016), Research Methods for Business Students (7th ed.), Pearson Education Limited, Edinburgh.

Sauser, B.J., Reilly, R.R. and Shenhar A.J. (2009), "Why projects fail? How contingency theory can provide new insights - A comparative analysis of NASA's Mars Climate Orbiter loss", International Journal of Project Management, Vol. 27 No. 7, pp. 665-679.

Shapira, Z. (2011), "I've Got a Theory Paper-Do You?: Conceptual, Empirical, and Theoretical Contributions to Knowledge in the Organizational Sciences", Organization Science, Vol.22 No. 5, pp. 1312-1321.

Sharma, S. and Rai, A. (2003), "An assessment of the relationship between ISD leadership characteristics and IS innovation adoption in organizations", Information \& Management, Vol. 40 No. 5, pp. 391-401.

Shi, Q. (2011), "Rethinking the implementation of project management: A Value Adding Path Map approach", International Journal of Project Management, Vol. 29 No. 3, pp. 295-302.

Silvius, G. (2016), “Social Project Management?”, in G. Silvius, Strategic Integration of Social Media into Project Management Practice, IGI Global, pp. 293-297.

Sowden, R. (eds.) (2008), "Portfolio, Programme and Project Management Maturity Model (P3M3)", available at: http://www.ogc.gov.uk/documents/p3m3.pdf (accessed on 28th January 2016). 
Stewart, D.W., Shamdasani, P.N. and Rook, D.W. (2007), Focus groups. Theory and practice $\left(2^{\text {nd }}\right.$ ed.), Sage Publications Inc., USA.

Svejvig, P. and Andersen, P. (2015), "Rethinking project management: A structured literature review with a critical look at the brave new world, "International Journal of Project Management, Vol. 33 No. 2, pp. 278-290.

Thomas, J. and Mullaly, M. (2008), Researching the value of project management, Management Institute, Inc, Project Newtown Square.

Van de Ven, A.H. and Drazin R. (1985), "The concept of fit in contingency theory. Research in Organizational Behavior”, Vol. 7, pp. 333-365.

Venkatesh, V. and Bala, H. (2008), "Technology Acceptance Model 3 and a Research Agenda on Interventions", Decision Sciences, Vol. 39 No. 2, pp. 273-315.

Yin, R.K., (2014), Case Study Research: Design and Methods (5th ed.), Sage

Publications, Inc., California.

Zhai, L., Xin, Y. and Cheng, C. (2009), "Understanding the value of project management from a stakeholder's perspective: Case study of mega-project management", Project Management Journal, Vol. 40 No. 1, pp. 99-109.

Zwikael, O. and Smyrk, J. (2012), "A general framework for gauging the performance of initiatives to enhance organizational value", British Journal of Management, Vol. 23 No. 1, pp. 6-22.

\section{Biographies}

Gabriela Fernandes is a Researcher and an Invited Assistant Professor at University of Minho (Portugal) on Project Management (PM). She spent 10 years in the coordination and management of projects in different industries. Throughout her career, she served as an executive director of some companies. She was responsible for various communications and author of several publications in the PM area. She developed and taught several PM training courses and as a consultant, coordinated the implementation of PM systems, as well as the implementation of PM office structures. She was director of the PMI Portugal Chapter, and is $\mathrm{PMP}^{\circledR}$ credential holder.

Madalena Araújo is a Chemical Engineer and holds M.Sc. in Industrial Management and Ph.D. in Production Engineering, both from Birmingham University (U.K.). She is Full Professor on Industrial and Technology Management at Minho University (Portugal), Production and Systems Department, School of Engineering. She is leader of the Industrial Engineering and Management Research Line of ALGORITMI Research Centre. Her research interests are on Economics of Engineering Systems and Management, mainly Decision and Utility Modelling, Project Evaluation and Management, Risk Analysis and their applications. She authored and coauthored around one hundred papers and supervised few dozen M.Sc. dissertations and Ph.D. theses.

Eduardo B. Pinto is a Programme Manager at CCG - University of Minho for multidisciplinary R\&D collaborative University-Industry funded contracts. He served as Executive Director of a Portuguese applied research institute between the University 
and Industry in the field of Information and Communication Technologies: CCG (www.ccg.pt ). He holds a degree in Industrial Electronics Engineering and a master's degree in Industrial Electronics - Automation and Robotics, both from the University of Minho. He is responsible for various communications and author of some publications in the area of University- Industry collaborations and his main research topics are in University-Industry Collaboration, Technological Change and Innovation and Knowledge creation \& sharing.

Ricardo J. Machado is a full professor of Information Systems Engineering and Technology at the University of Minho. His primary research interests are in modelling and requirements for information systems analysis and design and in process and project management lifecycles. He has supervised 10 completed $\mathrm{PhD}$ theses in these areas. He has published over 150 scientific publications and 4 industrial patents, and has acted as coordinator (PI) and senior researcher of over $50 \mathrm{R} \& \mathrm{D}$ projects. Currently, he is the director of the ALGORITMI Research Centre, the scientific coordinator of the EPMQ Laboratory at the CCG/ZGDV Institute, and the director of the Doctoral Programme in Advanced Engineering Systems for Industry. 